Original

\title{
Cholesterol Levels among Japanese Americans and Other Populations : Seattle Nikkei Health Study
}

\author{
T. Namekata ${ }^{1,3}$, D. Moore ${ }^{2}$, R. Knopp ${ }^{3}$, S. Marcovina ${ }^{3}$, E. Perrin ${ }^{3}$, \\ D. Hughes ${ }^{1}$, K. Suzuki ${ }^{4}$, M. Mori ${ }^{4}$, C. Sempos ${ }^{5}$, S. Hatano ${ }^{6}$, \\ C. Hayashi ${ }^{7}$, M. Hasegawa ${ }^{8}$
}

${ }^{1}$ Nikkei Disease Prevention Center, Seattle, Washington, U.S.A.

${ }^{2}$ University of Cincinnati, Ohio, U.S.A.

${ }^{3}$ University of Washington, Seattle, Washington, U.S.A.

${ }^{4}$ Epidemiological Arteriosclerosis Research Institute, Tokyo, Japan

${ }^{5}$ University of Illinois, Urbana/Champaign, Illinois, U.S.A., (formally at National Center for Health

Statistics, Centers for Disease Control and Prevention, Hyattsville, Maryland, U.S.A.)

${ }^{6}$ Shukutoku University, Chiba, Japan

${ }^{7}$ National Institute of Statistical Mathematics, Tokyo, Japan

${ }^{8}$ Toho University, Tokyo, Japan

\begin{abstract}
The purpose of this study was to compare average cholesterol levels between Seattle based Japanese Americans and three other populations : U.S. population, native Japanese population and native Japanese urban workers. A total of 1,466 Japanese Americans (724 men and 742 women) participated in cardiovascular disease screening in the Seattle area during 1989-94. Data sources for comparisons are from the Third National Health and Nutrition Examination Survey for 1988-91, the results of the National Cardiovascular Disease Examination Survey in Japan for 1990, and cardiovascular disease screening conducted by the Epidemiological Arteriosclerosis Research Institute in Japan for 1989. Total cholesterol and triglyceride levels of Seattle Japanese American men and women were highest among the four populations. Among men, high density lipoprotein cholesterol (HDL-C) levels for Seattle Japanese Americans and native Japanese were similar and fell between those of urban Japanese workers and the U.S. population. In women, the average HDL-C levels were highest in the Japanese urban workers, second highest in Seattle Japanese Americans, and lowest in both the U.S. population and native Japanese population. These differences in lipid levels may be caused by both genetic and environmental factors, which are now under investigation. J Atheroscler Thromb, $1996 ; 3$ : 105-113.
\end{abstract}

Key words : Lipid, Lipoprotein, Triglycerides, Cross-cultural comparison

It is well known that Japan's coronary heart disease (CHD) (ICD 410-414) mortality rate is the lowest among the industrialized nations (41.4 per 100,000 persons in 1992) (1), while that of the U.S.A. remains high $(188.2$ per 100,000 persons in 1992) (2). To examine the causes of such a

Address for correspondence: Tsukasa Namekata, Nikkei Disease Prevention Center, 1605 S. Washington St. Suite 5, Seattle, WA 98144

Received April 1, 1996

Accepted for publication June 3, 1996. difference in CHD mortality between the two nations, the $\mathrm{Ni}-\mathrm{Hon}-\mathrm{San}$ (Nippon-Honolulu-San Francisco Japanese) study was initiated in 1965 and CHD prevalence was found to be lowest in native Japanese, intermediate in Japanese Americans in Honolulu and highest in Japanese Americans in San Francisco (SF) (3). The investigators also reported lowest total cholesterol levels in native Japanese, intermediate in Honolulu Japanese and highest in SF Japanese (4), although differences in CHD among the three populations could be caused by other multiple factors as well. 
Because major changes in nutrition and other risk factors (e.g., cigarette smoking, blood pressure) have occurred both in Japan and in the United States over the past three decades, it is important to examine the current status of $\mathrm{CHD}$ risk factors in both countries. We conducted cardiovascular disease prevention screening which included a survey among Japanese Americans in Seattle. Our paper compares cholesterol levels between our study sample and others from the U.S. population and Japanese populations in Japan.

\section{Study Populations and Methods}

Cardiovascular disease prevention screening was conducted among Japanese Americans in the Seattle area (King County) from the fall of 1989 to the fall of 1994. Participants were recruited through a media campaign, flyers and household contacts. A total of 1,466 persons aged 30 years or older participated in the program with completion of screening tests and questionnaires. Japanese Americans on the West coast originated from Southern prefectures in Japan including Hiroshima, Okayama, and Yamaguchi. Immigration began more than one century ago; it was abruptly halted in 1924 with the passage of the Immigration Act and resumed in 1965 when the act was repealed. The term Nikkei refers to persons of Japanese ancestry, so that the study in Seattle was named the Seattle Nikkei Health Study. The composition of our study sample according to generation was as follows: $12.3 \%$ Issei (first generation), $49.4 \%$ Nisei (second generation), 37.0\% Sansei (third generation) and 1.3\% Yonsei (fourth generation).

A comparison between the study sample and the Japanese American population in King County from the 1990 U.S. census is presented in Table 1 (5). Our sample represented $12.7 \%$ of the Japanese American men and $10.3 \%$ of Japanese American women in the Seattle area. To better define the characteristics of our study sample, we conducted an additional survey on household income levels among the participants in 1994 and compared their income distribution with that of Japanese American households in the 1990 census (Fig. 1) (6). The distribution of our screening participants is slightly shifted to higher-income categories. We will discuss the possible impact of such income differences on lipid levels later.
Our results were compared with those from three populations : the U.S. population, the native Japanese population and Japanese urban workers in Japan. U.S. results were from phase 1 of the Third National Health and Nutrition Examination Survey (NHANES III) conducted in 1988-1991 (7). The data consists of a representative sample of the civilian noninstitutionalized population and thus reflects the racial composition of the U.S. which is comprised of $74.8 \%$ white, $11.9 \%$ black, 9.5\% Hispanic, $3.1 \%$ Asian and Pacific Islanders, and 0.7\% American Indian, Eskimo and Aleut (8). The native Japanese population data used was based on the National Cardiovascular Disease Examination Survey (NCDES) performed in 1990 and its samples were drawn randomly from the entire Japanese population (9). The samples from the Japanese urban workers were based on cardiovascular disease prevention screening conducted by the Epidemiological Arteriosclerosis Research Institute (EARI) in major cities throughout Japan including Tokyo, Chiba, Osaka, Sapporo, and Kitakyushu in 1989. The sample size, survey period, and whether lipid evaluation was conducted according to CDC quality control standards is shown in Table 2. Because of differences in age-breakdowns between the U.S. and Japan data, we used two sets of age-breakdowns for the Seattle sample: (A) and

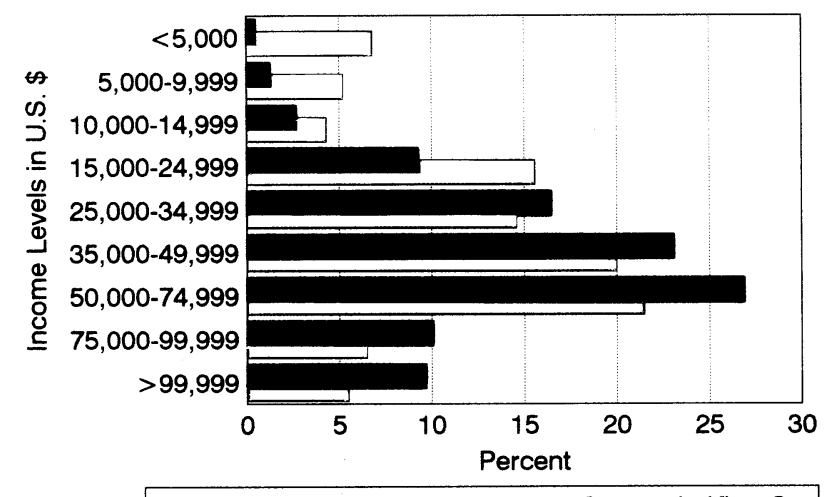

1994 Study Households $\square 1990$ Census in King Co.

Fig. 1. Comparison of the distribution of annual household incomes of 636 study participants and that of Japanese Americans in King County as reported by the U.S. Department of Commerce, the Bureau of Census.

Table 1. Age and sex-specific distribution of screening participants in Seattle and the total Japanese American population in King County, Washington, U.S.A.

\begin{tabular}{ccccr}
\hline Age & Male Participants & $\begin{array}{c}\text { Japanese Americans } \\
1990 \text { Census }\end{array}$ & Female Participants & $\begin{array}{c}\text { Japanese Americans } \\
1990 \text { Census }\end{array}$ \\
\hline $30-49$ & $238(7.0 \%)$ & 3405 & $248(6.6 \%)$ & 3785 \\
$50-69$ & $355(21.3 \%)$ & 1667 & $380(14.8 \%)$ & 2562 \\
$70+$ & $131(20.1 \%)$ & 651 & $114(13.5 \%)$ & 842 \\
Total & $724(12.7 \%)$ & 5723 & $742(10.3 \%)$ & 7189 \\
\hline
\end{tabular}


Table 2. The four populations used for comparison of lipoprotein and lipid levels. The table shows the survey periods under which the analysis was conducted, sample size of each population and whether the blood analysis was conducted under the Centers for Disease Control and Prevention (CDC) and the National Heart, Lung, and Blood Institute's (NHBLI) lipid standardization program.

\begin{tabular}{lccl}
\hline \multicolumn{1}{c}{ Population } & Survey Period & $\begin{array}{c}\text { Sample Size } \\
(\geq 30 \text { yrs old })\end{array}$ & \multicolumn{1}{c}{ Lipid Quality Control } \\
\hline Seattle Japanese Americans & $1989-1994$ & 1466 & Yes, CDC/NHLBI Program \\
U.S. Population & $1988-1991$ & $5475^{*}$ & Yes, CDC/NHLBI Program \\
Native Japanese & 1990 & 7906 & Yes, CDC/NHLBI Program \\
Japanese Urban Workers & 1989 & 146782 & $\begin{array}{l}\text { Yes, before screening, quality control exami- } \\
\text { nation was conducted }\end{array}$ \\
\hline
\end{tabular}

Note: *Persons 35 years old or over.

Table 3. The sample size of four populations used for lipoprotein and lipid comparisons.

\begin{tabular}{|c|c|c|c|c|c|}
\hline \multirow[t]{2}{*}{ Age } & \multicolumn{2}{|c|}{$\begin{array}{l}\text { Seattle Japanese } \\
\text { Americans }{ }^{1)}\end{array}$} & \multirow[t]{2}{*}{ U.S. Population²) } & \multirow[t]{2}{*}{ Native Japanese ${ }^{3)}$} & \multirow{2}{*}{$\begin{array}{l}\text { Japanese Urban } \\
\text { Workers }^{4}\end{array}$} \\
\hline & (A) & (B) & & & \\
\hline \multicolumn{6}{|l|}{ Males } \\
\hline 30-39 & 99 & & & 620 & 27,681 \\
\hline $35-44$ & & 128 & 303 & & \\
\hline $40-49$ & 139 & & & 788 & 45,727 \\
\hline $45-54$ & & 151 & 251 & & \\
\hline $50-59$ & 149 & & & 758 & 24,608 \\
\hline $55-64$ & & 163 & 253 & & \\
\hline $60-69$ & 206 & & & 674 & 6,724 \\
\hline $65-74$ & & 184 & 283 & & \\
\hline $70+$ & 131 & & & 456 & 651 \\
\hline $75+$ & & 61 & 229 & & \\
\hline \multicolumn{6}{|l|}{ Females } \\
\hline $30-39$ & 109 & & & 992 & 9,627 \\
\hline $35-44$ & & 128 & 335 & & \\
\hline $40-49$ & 139 & & & 1,124 & 15,150 \\
\hline $45-54$ & & 138 & 229 & & \\
\hline $50-59$ & 159 & & & 995 & 7,944 \\
\hline $55-64$ & & 184 & 233 & & \\
\hline $60-69$ & 221 & & & 870 & 1,794 \\
\hline $65-74$ & & 195 & 219 & & \\
\hline $70+$ & 114 & & & 629 & 172 \\
\hline $75+$ & & 44 & 233 & & \\
\hline
\end{tabular}

Data sources used for comparison are from the following sources :

1) Seattle Japanese Americans from the surveys conducted by Nikkei Disease Prevention Center for 1989-1994

2) The representative sample of the U.S. population from the NHANES III (1989-1991)

3) The representative sample of the native Japanese population from the National Cardiovascular Disease Survey in Japan for 1990

4) Japanese urban workers from the 1989 screening data collected by the Epidemiological Arteriosclerosis Research Institute.

(B) as shown in Table 3.

At the screening conducted in Seattle, venous blood samples were obtained after a 12 hour fast. Analysis was conducted at the University of Washington Northwest Lipid Research Laboratory, which participates in the Centers for Disease Control and Prevention/National Heart Lung and Blood Institute's lipid standardization program. Total cholesterol (TC) and triglyceride (TG) levels were measured enzymatically by Abbott Spectrum analyzer, and high density lipoprotein cholesterol (HDL-C) levels were measured by the dextran sulfate magnesium precipitation method (10). Regarding quality control in lipid measurements, the other three surveys adopted the $\mathrm{CDC} / \mathrm{NHLBI}$ program guidelines to some extent. According to the description of the study, NCDES did not require fasting prior to taking blood samples which may have had 
some impact on the accuracy of certain lipid measurements, particularly TG. This is also true for the data from EARI. We conducted quality control examinations at EARl's lab by shipping frozen serum samples twice from Seattle to EARI prior to the screening. After adjustment was made at EARl's lab based on the measurement values from the first serum samples, all measurement values except a few from the second samples were within the acceptable ranges.

The data from NHANES III were weighted to produce nationally representative results and the standard errors were computed using SUDAAN to account for the complex sample survey design (11). A t-test was conducted to examine the difference in means of TC, HDL-C and TG

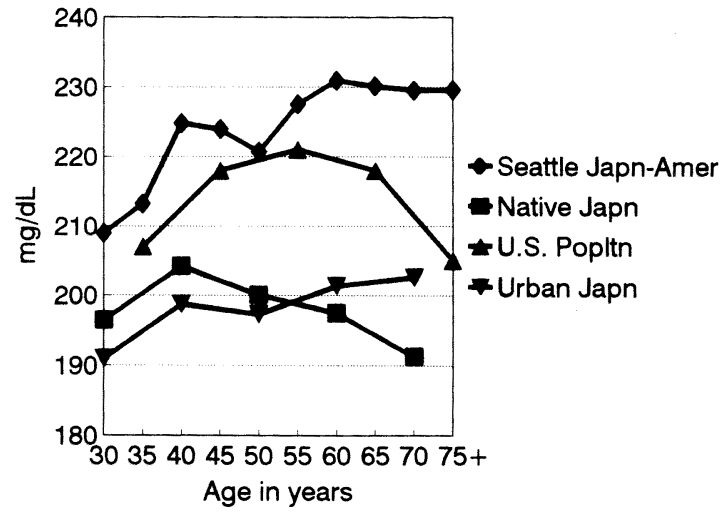

Fig. 2. Comparison of total cholesterol levels by age among four male populations: Seattle Japanese Americans, native Japanese population, Japanese urban workers and the U.S. population.

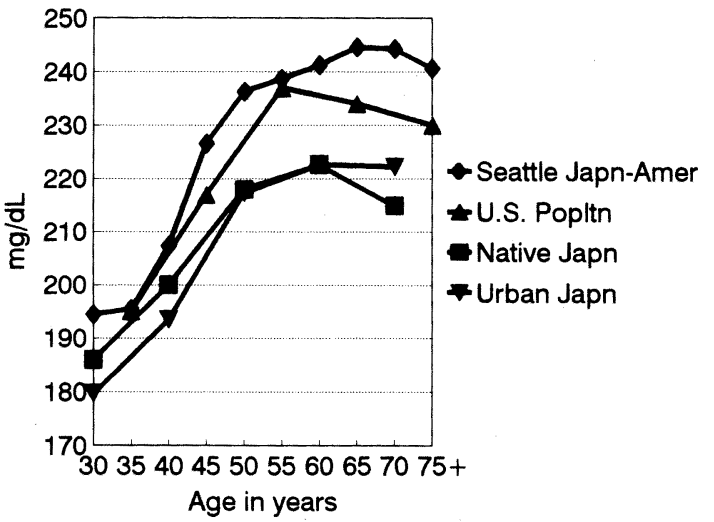

Fig. 3. Comparison of total cholesterol averages by age among four female populations: Seattle Japanese Americans, native Japanese population, Japanese urban workers and the U.S. population.

Table 4. The age-specific averages of total cholesterol levels in Seattle Japanese Americans, U.S. Population, native Japanese and Japanese urban workers.

\begin{tabular}{|c|c|c|c|c|c|c|c|c|}
\hline \multirow[t]{2}{*}{ Age } & \multicolumn{2}{|c|}{$\begin{array}{l}\text { Seattle Japanese } \\
\text { Americans }\end{array}$} & \multicolumn{2}{|c|}{ U.S. Population } & \multicolumn{2}{|c|}{ Native Japanese } & \multicolumn{2}{|c|}{ Japanese Urban Workers } \\
\hline & Mean & SD & Mean & SE & Mean & SD & Mean & SD \\
\hline \multicolumn{9}{|l|}{ Male } \\
\hline $30-39$ & 209.0 & 33.9 & & & $196.4^{* * *}$ & 35.1 & $190.9 * * *$ & 33.0 \\
\hline $35-44$ & 213.2 & 33.8 & $206.7^{*}$ & 2.3 & & & & \\
\hline $40-49$ & 224.8 & 37.9 & & & $204.2^{* * *}$ & 36.5 & $198.7^{* * *}$ & 34.8 \\
\hline $45-54$ & 223.9 & 38.8 & $218.1^{*}$ & 2.4 & & & & \\
\hline $50-59$ & 220.7 & 36.3 & & & $200.0 * * *$ & 36.5 & $197.2^{* * *}$ & 33.3 \\
\hline $55-64$ & 227.5 & 37.4 & $221.3^{*}$ & 2.5 & & & & \\
\hline $60-69$ & 230.9 & 40.2 & & & $197.4^{* * *}$ & 37.7 & $201.3^{* * *}$ & 31.6 \\
\hline $65-74$ & 230.1 & 39.7 & $217.7^{* * *}$ & 1.6 & & & & \\
\hline $70+$ & 229.5 & 37.0 & & & $191.2^{* * *}$ & 36.6 & $202.6^{* * *}$ & 35.6 \\
\hline $\begin{array}{l}75+ \\
\text { Females }\end{array}$ & 229.6 & 39.2 & $205.4^{* * *}$ & 2.8 & & & & \\
\hline $30-39$ & 194.4 & 31.4 & & & $185.9 * * *$ & 31.7 & $179.6^{* * *}$ & 28.4 \\
\hline $35-44$ & 195.4 & 29.8 & 194.7 & 1.4 & & & & \\
\hline $40-49$ & 207.3 & 36.0 & & & $200.0 * * *$ & 34.5 & $193.4^{* * *}$ & 32.0 \\
\hline $45-54$ & 226.6 & 38.4 & $216.8^{* * *}$ & 2.8 & & & & \\
\hline $50-59$ & 236.3 & 37.5 & & & $218.0^{* * *}$ & 36.8 & $217.3^{* * *}$ & 37.2 \\
\hline $55-64$ & 238.7 & 34.4 & 236.7 & 2.7 & & & & \\
\hline 60-69 & 241.2 & 37.9 & & & $222.6^{* * *}$ & 37.9 & $227.7^{* * *}$ & 35.2 \\
\hline $65-74$ & 244.5 & 41.2 & $234.3^{* * *}$ & 2.5 & & & & \\
\hline $70+$ & 244.2 & 42.6 & & & $214.9^{* * *}$ & 41.9 & $222.2^{* * *}$ & 45.1 \\
\hline $75+$ & 240.6 & 44.0 & 230.5 & 3.2 & & & & \\
\hline
\end{tabular}

Note: $\mathrm{SD}=$ standard deviation, $\mathrm{SE}=$ standard error

The $\mathrm{t}$-test was conducted between Seattle Japanese Americans and other populations.

Levels of significance are: ${ }^{*} p<.10,{ }^{* *} p<.05$ and ${ }^{* * *} p<.01$ 
between Seattle Japanese Americans and other populations by SPSS-PC 3.0 (12).

\section{Results}

A comparison of the average TC levels for men according to age-group was conducted among the four populations as shown in Fig. 2. TC levels were highest in Seattle Japanese Americans, second highest in the U.S. population and lowest in native Japanese and in Japanese urban workers. Average TC levels increased with age in all study populations except for native Japanese. As shown in Fig. 3, average TC levels for women indicate a similar trend regarding the order of TC levels among the populations. However, an increasing trend in TC levels with age was more pronounced in women than in men. Age-specific mean values of TC in the four populations are presented in Table 4. Significant differences in mean TC values between Seattle Japanese American and other populations are evident with the exception of U.S. women in the age groups 35-44, 55-64 and $75+$ years old.

A comparison of HDL-C levels is shown in Fig. 4 for men and Fig. 5 for women. Age-specific mean values of HDL-C for both sexes and t-test results are shown in Table 5. Unlike TC levels, no consistent patterns in $\mathrm{HDL}-\mathrm{C}$ levels with age were observed in the four populations in either sex. For men, the highest average HDL-C levels were observed in the urban Japanese workers and the lowest in the U.S. population. Both Seattle Japanese Americans and native Japanese came between the Japanese urban workers and the U.S. population. For women, the average $\mathrm{HDL}-\mathrm{C}$ levels were highest in the Japanese urban workers, second highest in Seattle Japanese Americans and lowest in both the U.S. and native Japanese populations.

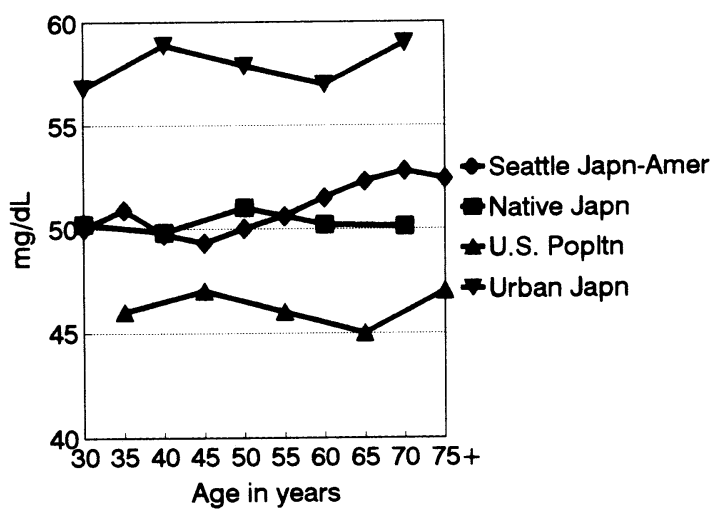

Fig. 4. Comparison of HDL-cholesterol averages by age among four male populations: Seattle Japanese Americans, native Japanese population, Japanese urban workers and the U.S. population.
TG levels among the four populations are shown in Fig. 6 for males and in Fig. 7 for females. There is little difference between TG levels for men aged 30-39 and 35-44 years old. However, at the age of 40-49 years, TG levels are highest in Seattle Japanese Americans, second highest in the U.S. population, third in native Japanese, and lowest in Japanese urban workers, with the exception of the appearance of the highest peak in the 45-54 year age-group of the U.S. population. After $40-49$ or $45-54$ years of age, TG levels for men tend to decline as age advances, while TG levels for women increase with aging in all four populations. Both TG levels of the Seattle Japanese Americans and the U.S. population are highest, those of the native Japanese were higher than those of urban Japanese workers who were lowest in both sexes.

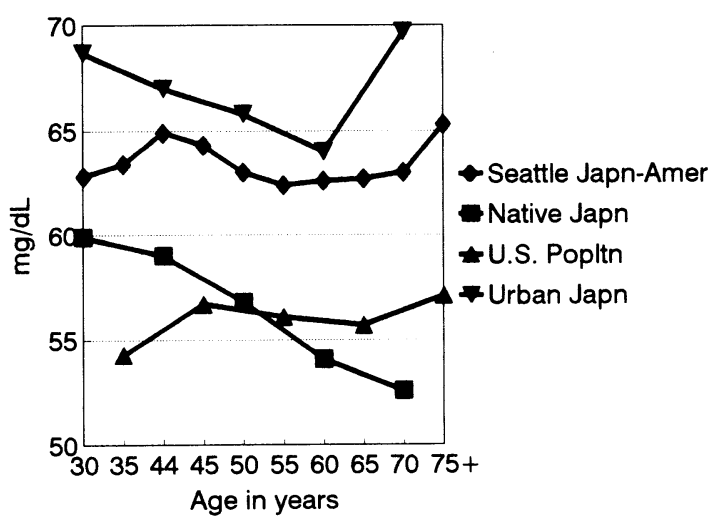

Fig. 5. Comparison of HDL-cholesterol averages by age among four female populations: Seattle Japanese Americans, native Japanese population, Japanese urban workers and the U.S. population.

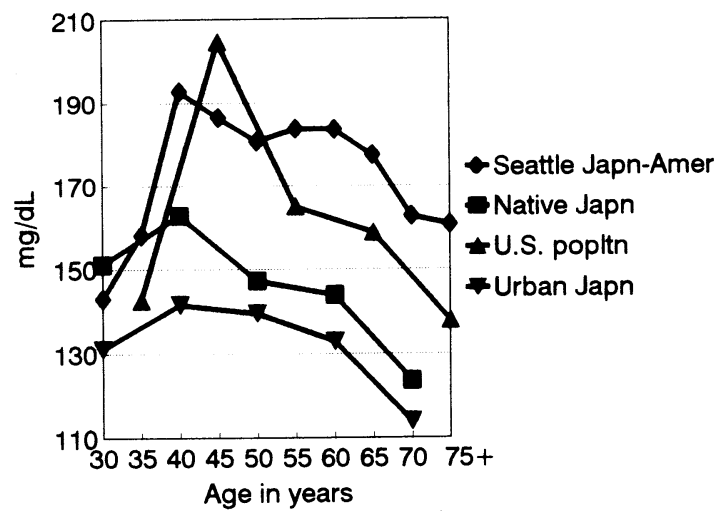

Fig. 6. Comparison of triglyceride averages by age among four male populations: Seattle Japanese Americans, native Japanese population, Japanese urban workers and the U.S. population. 


\section{Discussion}

With regard to the representativeness of the Japanese American population in King county (the Seattle area), we compared the household income levels between the population in the 1990 Census (6) and our 1994 samples

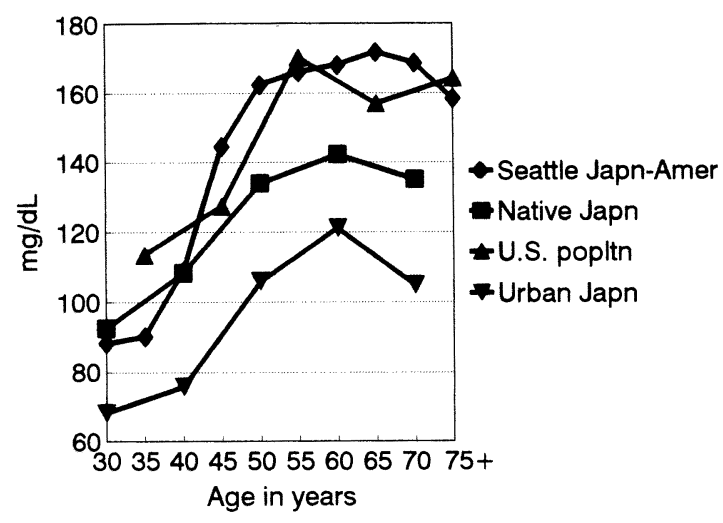

Fig. 7. Comparison of triglyceride averages by age among four female populations: Seattle Japanese Americans, native Japanese population, Japanese urban workers and the U.S. population. for which we conducted a follow-up survey. Out of 673 households of the study participants, 511 households $(76 \%)$ have responded so far. As shown in Fig. 4 , the distribution of our study sample, (annual median income: $\$ 46,000$ ) is shifted towards a higher income level than the total population (annual median income: $\$ 37,244$ ). The four-year gap between our survey and the census survey possibly contributed to slightly higher observed income levels in our study sample due to the time-related effects of inflation.

Regarding differences in sample characteristics according to the year of participation, such differences might exist but are considered to be insignificant: the proportion of current drinkers was $63 \%$ for men and $42 \%$ for women among the participants screened between $1989-1992$ vs. $65 \%$ for men and $46 \%$ for women among the 1989-1994 participants ; and the proportion of current smokers was $15 \%$ for men and $10 \%$ for women among the 1989-1992 participants vs. $15 \%$ for men and 10\% for women among the 1989-1994 participants.

Because the Seattle study participants were volunteers, we are concerned about response bias. At present we have no definitive method to ascertain whether our sample is biased, with the exception of comparing household incomes as described above. The Honolulu Heart Study

Table 5. The age-specific averages of HDL-cholesterol levels in Seattle Japanese Americans, U.S. population, native Japanese, and Japanese urban workers.

\begin{tabular}{|c|c|c|c|c|c|c|c|c|}
\hline \multirow{2}{*}{ Age } & \multicolumn{2}{|c|}{$\begin{array}{l}\text { Seattle Japanese } \\
\text { Americans }\end{array}$} & \multicolumn{2}{|c|}{ U.S. Population } & \multicolumn{2}{|c|}{ Native Japanese } & \multicolumn{2}{|c|}{ Japanese Urban Workers } \\
\hline & Mean & SD & Mean & SE & Mean & SD & Mean & $\mathrm{SD}$ \\
\hline \multicolumn{9}{|l|}{ Male } \\
\hline $30-39$ & 50.0 & 12.6 & & & 50.2 & 15.1 & $56.8^{* * *}$ & 13.4 \\
\hline $35-44$ & 50.9 & 13.0 & $46.3^{* * *}$ & 1.0 & & & & \\
\hline $40-49$ & 49.7 & 14.1 & & & 49.8 & 14.2 & $58.9 * * *$ & 15.4 \\
\hline $45-54$ & 49.3 & 14.4 & $46.6 *$ & 0.8 & & & & \\
\hline $50-59$ & 50.0 & 14.0 & & & 51.0 & 14.6 & $57.9 * * *$ & 14.5 \\
\hline $55-64$ & 50.6 & 13.3 & $45.6 * * *$ & 0.8 & & & & \\
\hline $60-69$ & 51.5 & 13.2 & & & 50.2 & 16.0 & $57.0 * * *$ & 15.0 \\
\hline $65-74$ & 52.3 & 14.8 & $45.3^{* * *}$ & 0.8 & & & & \\
\hline $70+$ & 52.8 & 15.8 & & & $50.1^{*}$ & 15.5 & $59.0^{* * *}$ & 16.1 \\
\hline $\begin{array}{l}75+ \\
\text { Females }\end{array}$ & 52.4 & 15.7 & $47.2 * *$ & 0.8 & & & & \\
\hline $30-39$ & 62.8 & 15.3 & & & $59.9 * *$ & 14.1 & $68.7^{* * *}$ & 14.6 \\
\hline $35-44$ & 63.4 & 15.8 & $54.3^{* * *}$ & 0.9 & & & & \\
\hline $40-49$ & 64.9 & 17.1 & & & $59.0 * * *$ & 15.0 & $67.0 *$ & 15.1 \\
\hline $45-54$ & 64.3 & 17.3 & $56.8 * * *$ & 0.8 & & & & \\
\hline $50-59$ & 63.0 & 16.1 & & & $56.8^{* * *}$ & 15.5 & $65.8^{* *}$ & 15.4 \\
\hline $55-64$ & 62.4 & 15.9 & $56.1^{* * *}$ & 0.9 & & & & \\
\hline $60-69$ & 62.6 & 16.6 & & & $54.1^{* * *}$ & 14.3 & 64.0 & 16.2 \\
\hline $65-74$ & 62.7 & 17.7 & $55.7^{* * *}$ & 0.8 & & & & \\
\hline $70+$ & 63.0 & 18.7 & & & $52.6 * * *$ & 15.2 & $69.7^{* * *}$ & 13.8 \\
\hline $75+$ & 65.3 & 19.5 & $57.1^{* * *}$ & 1.1 & & & & \\
\hline
\end{tabular}

Note : $\mathrm{SD}=$ standard deviation, $\mathrm{SE}=$ standard error

The $\mathrm{t}$-test was conducted between Seattle Japanese Americans and other populations.

Levels of significance are: ${ }^{*} p<.10,{ }^{* *} p<.05$ and ${ }^{* * *} p<.01$ 
Table 6. The age-specific averages of triglycerides in Seattle Japanese Americans, U.S. population, native Japanese and Japanese urban workers

\begin{tabular}{|c|c|c|c|c|c|c|c|c|}
\hline \multirow{2}{*}{ Age } & \multicolumn{2}{|c|}{$\begin{array}{c}\text { Seattle Japanese } \\
\text { Americans }\end{array}$} & \multicolumn{2}{|c|}{ U.S. Population } & \multicolumn{2}{|c|}{ Native Japanese } & \multicolumn{2}{|c|}{ Japanese Urban Workers } \\
\hline & Mean & SD & Mean & SE & Mean & SD & Mean & SD \\
\hline \multicolumn{9}{|l|}{ Male } \\
\hline $30-39$ & 143.1 & 107.1 & & & 151.2 & 97.9 & 131.1 & 106.3 \\
\hline $35-44$ & 158.1 & 141.6 & $142.7^{* * *}$ & 7.3 & & & & \\
\hline $40-49$ & 192.8 & 218.3 & & & $162.8^{* *}$ & 122.3 & $141.6^{* * *}$ & 124.4 \\
\hline $45-54$ & 186.5 & 196.2 & 204.7 & 33.8 & & & & \\
\hline $50-59$ & 180.7 & 138.6 & & & $147.2^{* * *}$ & 105.5 & $139.5^{* * *}$ & 93.0 \\
\hline $55-64$ & 183.7 & 136.2 & 165.0 & 8.9 & & & & \\
\hline $60-69$ & 183.6 & 209.9 & & & $143.9 * * *$ & 98.4 & $132.9 * * *$ & 111.0 \\
\hline $65-74$ & 177.4 & 265.9 & $158.8^{*}$ & 8.4 & & & & \\
\hline $70+$ & 162.7 & 214.1 & & & $123.6^{* * *}$ & 73.2 & $113.9 * * *$ & 81.6 \\
\hline $\begin{array}{l}75+ \\
\text { Females }\end{array}$ & 160.7 & 97.7 & 137.9 & 6.1 & & & & \\
\hline $30-39$ & 88.2 & 49.3 & & & 92.5 & 56.0 & $68.2^{* * *}$ & 41.2 \\
\hline $35-44$ & 90.2 & 51.6 & 113.4 & 8.0 & & & & \\
\hline $40-49$ & 108.8 & 122.2 & & & 108.2 & 78.1 & $75.8^{* * *}$ & 38.6 \\
\hline $45-54$ & 144.6 & 157.1 & 127.3 & 6.4 & & & & \\
\hline $50-59$ & 162.4 & 145.9 & & & $133.8^{* * *}$ & 84.5 & $105.9 * * *$ & 64.3 \\
\hline $55-64$ & 166.0 & 131.9 & $170.3^{*}$ & 10.5 & & & & \\
\hline $60-69$ & 168.1 & 115.9 & & & $142.2^{* * *}$ & 85.6 & $121.1^{* * *}$ & 79.9 \\
\hline $65-74$ & 171.8 & 114.4 & $156.9 *$ & 9.2 & & & & \\
\hline $70+$ & 168.7 & 104.4 & & & $135.0^{* * *}$ & 78.5 & $104.8^{* * *}$ & 36.1 \\
\hline $75+$ & 158.3 & 77.5 & $164.2^{*}$ & 13.7 & & & & \\
\hline
\end{tabular}

Note : $\mathrm{SD}=$ standard deviation, $\mathrm{SE}=$ standard error

The t-test was conducted between Seattle Japanese Americans and other populations.

Levels of significance are: ${ }^{*} p<.10,{ }^{* *} p<.05$ and ${ }^{* * *} p<.01$

stated that the men who participated smoked less, had a slightly higher body mass index (BMI), a higher level of education, a lower percentage of non-married status and a lower coronary heart disease incidence rate than nonparticipants (13). Jones et al. reported that the participants in their screening program had a lower BMI, lower mean cholesterol level, lower mean systolic and diastolic blood pressure level and a higher education level than non-participants (14). If the findings from these studies are applied to our study, it is likely that non-participants of Seattle Japanese Americans would be less healthy in terms of cardiovascular health than our study participants. Thus, true values for mean lipid and lipoprotein levels among the Seattle Japanese American population may possibly be even less favorable than the observed values in our study.

Fasting requirements were different between the four populations used in our comparison. For native Japanese and native Japanese urban workers, fasting prior to blood collection was not required, whereas among Japanese Americans and the general U.S. populations, a 12 hour fasting requirement was imposed. Non-fasting status has been shown to influence TG levels. The NCDES report shows an inverse relationship between average TG levels and the number of fasting hours before blood sample collection: $141.0 \mathrm{mg} / \mathrm{dl}$ among those with less than 3-hours of fasting, $132.0 \mathrm{mg} / \mathrm{dl}$ among those with 3 to 6 hours of fasting and $116.2 \mathrm{mg} / \mathrm{dl}$ among those with more than 6 hours of fasting. The average TG of the entire sample was $132.1 \mathrm{mg} / \mathrm{dl}$ which is much higher than that for 6 or more hours of fasting (9). Thus, the agespecific average TG values of the native Japanese and Japanese urban workers used in our analysis are most likely to be overestimated as compared to fasting TG levels of Japanese Americans and the general U.S. population. In the United States, there has been a $15 \mathrm{mg} / \mathrm{dl}$ decline in total serum cholesterol for U.S. adults in the thirty years between the First National Health Examination Survey for 1960-1962 and the Third National Health Examination Survey for 1988-1991 (7). Possible factors that may have contributed to this decline are an extensive nutrition education (15), health promotion and disease prevention activities (16), decreased consumption of certain high-fat foods (17), increased use of lipid lowering diets and drugs (18), increased use of post-menopausal estrogen replacement therapy (19) and the development of lower-dose oral contraceptives (19), in addition to the extensive efforts of the National Cholesterol Education Program (NCEP) $(20,21)$.

In Japan, on the other hand, an increase in average 
total cholesterol levels for both Japanese men and women was observed from 1980 to 1990 according to the National Survey : $12.2 \mathrm{mg} / \mathrm{dl}$ for men and $16.0 \mathrm{mg} / \mathrm{dl}$ for women 30 years old and over (9). This increase may be due to the westernization of the Japanese diet which includes higher amounts of animal fat and protein. Between 1980 and 1990 , the consumption of animal protein in Japan rose from 39.2 grams per capita to 41.4 grams and the consumption of animal fat rose from 26.9 grams to 27.5 grams per capita (1).

Kitamura et al. conducted cardiovascular risk surveys among Japanese urban male workers in Osaka (22), showing similar trends in TC and HDL-C to those of the urban workers from EARI. Mean TC levels were 194.7 $\mathrm{mg} / \mathrm{dl}$ for $40-44$ years old, $199.7 \mathrm{mg} / \mathrm{dl}$ for $45-49$ years old, $199.7 \mathrm{mg} / \mathrm{dl}$ for $50-54$ years old and $205.1 \mathrm{mg} / \mathrm{dl}$ for 55-59 years old among Osaka male workers, compared with $198.7 \mathrm{mg} / \mathrm{dl}$ for $40-49$ years old and $197.2 \mathrm{mg} / \mathrm{dl}$ for 50-59 years old among urban male workers fm EARI. Mean HDL-C levels were $56.5 \mathrm{mg} / \mathrm{dl}$ for $40-44$ years old, $56.1 \mathrm{mg} / \mathrm{dl}$ for $45-49$ years old, $58.1 \mathrm{mg} / \mathrm{dl}$ for $50-54$ and $55.7 \mathrm{mg} / \mathrm{dl}$ for 55-59 years old among Osaka male workers, compared with $58.9 \mathrm{mg} / \mathrm{dl}$ for $40-49$ years old and $57.9 \mathrm{mg} / \mathrm{dl}$ for $50-59$ years old among urban male workers from EARI. Based on results from EARI and Kitamura et al., both male and female Japanese urban workers have lower mean TC levels and higher HDL-C levels than the average Japanese population, partly because company workers in Japan are a selected healthy group and partly because they might have a lifestyle which is more favorable concerning cardiovascular health.

There are striking differences between TC levels reported from the $\mathrm{Ni}-\mathrm{Hon}-\mathrm{San}$ study which examined three Japanese male populations between 1965-70 (4) and our findings. The average TC level of Hiroshima based Japanese men was less than $180 \mathrm{mg} / \mathrm{dl}$ twenty-five years ago, whereas the average TC level of native Japanese rose to between 191 and $204 \mathrm{mg} / \mathrm{dl}$ in 1990. It is also surprising that current TC levels of Seattle Japanese Americans are quite similar to that of San Francisco Japanese Americans 25 years ago; both populations showed average cholesterol levels ranging from 220-230 $\mathrm{mg} / \mathrm{dl}$ depending on age. This suggests that as the Japanese lifestyle and diet become increasingly westernized, the low risk status for CHD may be lost. We previously reported that Seattle Japanese Americans have a higher average BMI than native urban Japanese (23). Fujimoto et al. reported a higher prevalence of diabetes among Seattle Japanese Americans than U.S. whites or native urban Japanese (24). These factors may partly account for the observed differences in cholesterol levels. The association between environmental factors and lipid and lipoprotein levels in Japanese Americans and native Japanese are currently under our investigation.

It is interesting to note that consistent trends in choles- terol levels between the sexes were observed in all four study groups. TC and TG levels in women rose dramatically after ages $45-50$ years at which time menopause typically begins. Average TC levels in premenopausal women were lower than in men, whereas postmenopausal women had higher average TC levels than men. Average TG levels for women remained lower than those of men for all age groups. Estrogen is considered to confer a protective benefit against cardiovascular disease which is mediated in part by its effects on lipoprotein metabolism (25). After menopause, risk factors have been shown to increase, Mathews et al. found HDL-C and LDL-C underwent greater menopause-related changes than those associated with aging in the absence of menopause (26).

It is impossible to predict if the incidence and mortality of CHD among Japanese would reach the rate of Americans as TC levels of native Japanese approach that of Americans. Such a question would be answered by future studies because the impact of cholesterol changes on CHD incidence or mortality in a population may take many years before any significant change is observed. Furthermore, there are multiple factors contributing to $\mathrm{CHD}$ which need to be examined as well.

As far as CHD mortality is concerned, there still exists a large gap between Japan and the United States (41.4 per 100,000 persons and 188.2 per 100,000 persons, respectively) $(1,2)$. Therefore, the risks for $\mathrm{CHD}$ in the United States need to be reduced. Despite the national campaign to lower cholesterol levels in the United States (20), Seattle Japanese Americans' TC levels were higher than those of the U.S. population. Thus, an investigation is needed to examine the cause of elevated TC levels among Seattle Japanese Americans, and further health promotion and education is essential to lower cardiovascular disease risks for this minority population.

Acknowledgement: We would like to express our sincere appreciation to the staff at the University of Washington Northwest Lipid Research Clinic and Laboratories, Seattle, Washington, U.S.A. for their wonderful assistance and cooperation.

\section{References}

(1) Health and Welfare Statistics Association: Trends in Nation's Health, Journal of Health and Welfare Statistics (Kosei no shihyo), Special issue, 41: 402, 93-97, 1994

(2) U.S. Dept of Health and Human Services: Monthly vital statistics report, $41: 25,1993$

(3) Marmot MG and Syme SL: Acculturation and Coronary Heart Disease in Japanese-Americans. Am J Epidemiol, 104: 225-247, 1976

(4) Kagan A, Harris BR, Winkelstein W Jr, Jownson KG, Kato $H$, Syme SL, Rhoads GG, Gay ML, Nichaman MZ, Hamilton HB, and Tillotson J: Epidemiologic Studies of Coronary Heart Disease and Stroke in Japanese Men Living in Japan, Hawaii and California: Demographic, 
Physical, Dietary and Biochemical Characteristics. J Chron Dis, 27 : 345-364, 1974

(5) U.S. Dept of Commerce, Bureau of Census : 1990 Census of Population, General Population Characteristics: Washington, 1990 CP-1-49, p. 141, 1992

(6) U.S. Dept of Commerce, Bureau of Census : 1990 Census of Population, Social and Economic Characteristics: Washington, 1990 CP-2-49, p. 374, 1992

(7) Johnson CL, Rifkind BM, Sempos CT, Carroll MD, Bachorik PS, Briefel RR, Gordon DJ, Burt VL, Brown CD, Lippel K, and Cleeman JI: Declining serum total cholesterol levels among US adults. The National Health and Nutrition Examination Surveys. JAMA, 269 : 3002-3008, 1993

(8) Statistical Abstract of the United States 1994. U.S. Department of Commerce. Economics and Statistics Administration. Bureau of the Census. 114th Ed p. 22, 1994

(9) Ministry of Health and Welfare, Bureau of Health and Medical Care, Division of Disease Prevention : Summary of the 4th National Cardiovascular Disease Examination Survey (1990), Journal of Health and Welfare Statistics (Kosei no shihyo), 40: 36-48, 1993

(10) University of Washington Northwest Lipid Research Laboratories: Anal Proc, 1991

(11) Shah BV, Barnell BG, Hunt PN, et al : SUDAAN users manual release 6.30. Research Triangle Park, NC: Research Triangle Institute, 1991

(12) SPSS Inc. SPSS-X User's Guide, 3rd Ed, 1988

(13) Benfante R, Reed D, MacLean C, and Kagan A: Response bias in the Honolulu Heart Program. Am J Epidemiol, 130 : 1088-1100, 1989

(14) Jones $A$, Cronin PA, Bowen $M$ : Comparison of risk factors for coronary heart disease among attenders and non-attenders at a screening programme. $\mathrm{Br} J$ Gen Practice, 43: 375-7, 1993

(15) Nutrition and Your Health: Dietary Guidelines for Americans. 3rd Ed, Washington, DC : US Dept of Agriculture and Dept of Health and Human Services, 1990

(16) National Research Council. Diet and Health : Implications for Reducing Chronic Disease Risk, Washington, DC : Nat Acad Press, 1989

(17) Rizek RL and Jackson EM : Current Food Consumption
Practices and Nutrient Sources in the American Diet. Hyattsville, Md, US Dept of Agriculture, Consumer Nutrition Center-Human Nutrition Sciences and Education Administration, 1980

(18) Schucker B, Wittes JT, Santanello NC, Weber SJ, McGoldrick D, Donato $K$, Levy A, Rifkind BM: Change in cholesterol awareness and action: Results from national physician and public surveys. Arch Intern Med, 151: 666-673, 1991

(19) Burkman RT : Lipid and lipoprotein changes in relation to oral contraception and hormonal replacement therapy. Fertil Steril, 49 (suppl 2) : 39S-50S, 1988

(20) National Cholesterol Education Program. Report of the expert panel on population strategies for blood cholesterol reduction. Circulation, 83: 2154-2232, 1991

(21) National Cholesterol Education Program. Report of the NCEP expert panel on detection, evaluation, and treatment of high blood cholesterol in adults. Arch Intern Med, 148: 36-39, 1988

(22) Kitamura $A$, Iso $H$, Naito $Y$, lida $M$, Konishi $M$, Folsom $A R$, Sato S, Kiyama M, Nakamura M, Sankai T, Shimamoto T, and Komachi $Y$ : High-density lipoprotein cholesterol and premature coronary heart disease in urban Japanese men, Circulation, 89 : 2533-2539, 1994

(23) Namekata T, Moore D, Suzuki K, Knopp RH, Marcovina SM, Perrin EB, Hayashi C, and Hatano S: A study of the association between cholesterol and lifestyle factors among Seattle Japanese Americans. J Health Welfare Stat, $42: 16-21,1995$

(24) Fujimoto WY, Bergstrom RW, Bokyo EJ, Kinyoun JL, Leonetti DL, Newel-Morris LL, Robinson LR, Shuman WP, Stolov WC, Tsunehara $\mathrm{CH}$, and Wahl PW: Diabetes and diabetes risk factors in second-and third-generation Japanese Americans in Seattle, Washington. Diabetes Res Clin Pract, 24 (Suppl): S43-S52, 1994

(25) Knopp $\mathrm{RH}$, Xiadong $Z$ and Barolome B: Effects of estrogens on lipoprotein metabolism and cardiovascular disease in women. Atherosclerosis 110 (Suppl): S83S91, 1994

(26) Mathews KA, Meilagn E, Kuller LH, Kelsey SF, Caggiula AW, and Wing RR: Menopause and risk factors for coronary heart disease. N Engl J Med,321 : 641-6. 1989 